\title{
Cabouret M. (2005). - La Finlande
}

Paris, Karthala, 490 p.

\section{Simon Edelblutte}

\section{(2) OpenEdition}

\section{Journals}

Édition électronique

URL : http://journals.openedition.org/rge/350

DOI : $10.4000 /$ rge. 350

ISSN : 2108-6478

Éditeur

Association des géographes de l'Est

Édition imprimée

Date de publication : 1 juin 2005

Pagination : 219-220

ISSN : 0035-3213

Référence électronique

Simon Edelblutte, «Cabouret M. (2005). — La Finlande », Revue Géographique de l'Est [En ligne], vol. 45 / 3-4 | 2005, mis en ligne le 18 décembre 2009, consulté le 25 septembre 2020. URL : http:// journals.openedition.org/rge/350; DOI : https://doi.org/10.4000/rge.350

Ce document a été généré automatiquement le 25 septembre 2020

Tous droits réservés 


\section{Cabouret M. (2005). - La Finlande}

Paris, Karthala, 490 p.

\section{Simon Edelblutte}

\section{RÉFÉRENCE}

Cabouret M. (2005). — La Finlande, Paris, Karthala, 490 p.

\section{NOTE DE L'ÉDITEUR}

Le professeur Michel Cabouret, qui a longtemps enseigné à l'université de Metz, nous a quittés le 30 novembre 2005. C'est évidemment avec beaucoup de tristesse que l'ensemble de ses collègues et amis, nombreux à l'Association des Géographes de l'Est, ont appris cette nouvelle. Nous exprimons à sa famille nos plus sincères condoléances et nous publierons dans le prochain numéro de la RGE un « in memoriam » rappelant la carrière de Michel cabouret. Il se trouve qu'au moment du décès de notre collègue et ami, nous avions reçu son dernier ouvrage consacré à l'un de ces pays de l'Europe du Nord dont il était le grand spécialiste. Nous en publions ici le compte-rendu.

M. Deshaies

1 En un gros volume de presque 500 p., Michel Cabouret, seul spécialiste de l'Europe du Nord dans notre discipline, nous offre une étude très documentée et précise sur un pays peu étudié par les chercheurs français et encore moins par les géographes ; Michel Cabouret ne cite d'ailleurs lui-même, dans l'abondante bibliographie commentée qu'il propose à la fin de son travail, que deux ouvrages francophones portant spécifiquement sur la géographie de la Finlande et datant respectivement de1958 et $1986 \ldots$

2 Le livre fait partie de la collection «Hommes et sociétés " des éditions Kartahla et comporte 34 cartes et figures, de nombreux tableaux et schémas, ainsi qu'un encart couleur central regroupant une cinquantaine de photos de l'auteur. Il se divise en 4 
grandes parties dont trois sont sensiblement égales en nombre de pages (150 p.) et l'une beaucoup plus courte ( 50 p.) : elles sont divisées en 23 sous-parties au total.

3 La première partie traite du milieu et de la population, la seconde de l'évolution historique et économique, la troisième - la plus courte - de la société finlandaise et la dernière est une étude régionale du pays. Ce recensement des parties montre que le travail va bien au-delà d'une simple étude géographique, traitant largement d'aspects historiques, économiques, sociaux et culturels. Le tout s'appuie sur des informations extrêmement nombreuses et très précises grâce à des données issues de recensements récents.

4 À côté de parties plus conventionnelles (le milieu avec le relèvement isostatique, l'histoire politique et les rapports avec l'URSS - la finlandisation...) car en partie traitées ailleurs - comme dans la Géographie Universelle de 1996 - plusieurs développements dont on ne peut trouver l'équivalent en français par ailleurs sont particulièrement intéressants et permettent au lecteur francophone de compléter ses connaissances sur ce pays.

On peut citer tout ce qui traite de l'évolution du pays dans plusieurs domaines depuis son intégration à l'Union Européenne (UE) en 1995, avec en particulier des informations sur :

- le secteur agricole et la prise en compte (en commun avec la Suède) de « la dimension nordique » permettant à l'Etat de subventionner directement les agriculteurs tout en recevant en plus des aides européennes au titre du développement des régions périphériques (p. 225) ;

- la politique régionale, avec la refonte du découpage administratif en 1997, par le remplacement des 11 lääni/län (régions) par 5 grandes régions, elles-mêmes divisées en 19 petites régions, le tout étant mieux adapté à la fois au versement des subventions de l'UE et à la gestion d'infrastructures intercommunales. La réforme de 1997 est aussi à l'origine de la mise au point d'instances démocratiques régionales dans un pays qui était le seul en Europe à ne pas en avoir entre celles de la commune et celles de l'Etat (p. 142-149).

Mais d'autres développements sont particulièrement passionnants, comme par exemple :

- la mise en place du réseau urbain du pays au fil des siècles avec l'adaptation des plans aux risques d'incendies très forts dans des villes construites, jusqu'au début du XXe siècle, presque exclusivement en bois, puis leur progressif remplacement par des constructions en pierre (p. 124-125);

- l'étude des liens entre agriculture (une autre des spécialités de l'auteur) et forêt qui, en plus d'être une des ressources économiques essentielles du pays (la Finlande assure 7,6 \% de la valeur totale du commerce mondial des produits de la forêt en 1997, p. 228 ; l'exploitation et les industries de première transformation du bois assurent 7,9 \% du PIB en 1998, p. 242), « appartient au patrimoine de l'identité finlandaise » p. 237 ;

- le retournement industriel du pays passé d'une industrie sous la dépendance des importations soviétiques à une industrie moderne, innovante et compétitive symbolisée par la réussite de la première entreprise nationale, Nokia (p. 253), cependant sensible récemment au retournement de la conjoncture sur un marché du matériel de téléphonie mobile très dépendant des exportations (p. 259);

- enfin, en quatrième partie, sont présentées des études régionales d'une grande précision, avec en particulier des développements (d'ailleurs présents aussi dans les parties thématiques) sur l'archipel d'Ahvenanmaa/Åland, qui bénéficie au milieu de la mer Baltique 
et à mi-chemin entre Suède et Finlande, d'un statut administratif particulier en tant que province (maakuntaa/landskap) et non région (lääni/län), en raison de son peuplement presque exclusivement suécophone. Ce statut lui accorde une très large autonomie au sein de la Finlande et lui permet d'accueillir, pour une très courte escale, les ferries reliant Stockholm à Helsinki, autorisant ainsi la vente d'alcool détaxé aux passagers... L'auteur attache par ailleurs un respect particulier au bilinguisme officiel de la Finlande qui compte 5,7 \% de suécophones, notamment sur ses littoraux Sud et Ouest (p. 105-107) et les noms de lieux sont systématiquement traduits dans les deux langues (finnois/suédois) pour éviter toute confusion au cours de la lecture.

7 Si ce gros ouvrage souffre de quelques défauts mineurs certainement plus dus à des contraintes éditoriales qu'à une volonté de l'auteur (très petites photos toutes regroupées dans un encart central, erreurs dans la numérotation de cartes, quasiabsence de cartes régionales dans la quatrième partie), il reste un formidable recueil d'informations variées s'étendant bien au-delà de la seule géographie de la Finlande. Ce panorama détaillé où transparaît le respect de l'auteur pour « un petit peuple acharné au travail » (p. 91), est le fruit d'une impressionnante érudition et d'une maîtrise tout aussi impressionnante du «terrain » d'étude.

\section{AUTEURS}

\section{SIMON EDELBLUTTE}

Université Nancy 2 